satellites. The energy evolved/unit weight when the cubje phase crystallizes ( $200 \mathrm{cal} / \mathrm{g}$ ) is considered to be competitive with that generated by electrical batteries.

R. P. Millek

R. A. Mercer

National Chemical Laboratory,

Teddington, Middlesex.

' Mercer, R. A., and Miller, R. P., J. Sci. Instr., 40, 352 (1963),

"Mercer, R. A., and Miller, R. P., Nature, 197, 683 (1963).

${ }^{3}$ Potter, R. A., and Harris, L. A., J. Amer. Ceram. Soc., 45 (12), 615 (1962).

4 Harris, L. A., Potter, R. A., and Yakel, H. L., Acta Cryst., 15, 615 (1962)

' Dietzel, A., Glastech., 22, 41 (1948).

' Glascock, H. H., J. App. Phys., 33, 3296 (1962).

\section{Condensation Coefficient of Water}

THE condensation coefficient of a liquid has been defined $^{1}$ as the fraction of the number of molecules impinging on a gas-liquid interface that actually condense. It has been measured for water by many workers (for example, refs. 2-4), who have obtained values ranging from 0.003 to $1 \cdot 0$. The possibility that its true value might be quite low is of practical importance in the design of condensers ${ }^{5}$, and a new determination is, therefore, being made.

The method developed here is completely different from all previous methods. Basically a known area of pure water is exposed, for a very short time, to an atmosphere of steam labelled with tritium. A cylindrical jet of inactive water is passed through the radioactive steam to a receiver. The number of molecules impinging on the steam-water interface is calculated from the area of the water jet and the temperature and pressure of the steam. The number of steam molecules that have condensed is determined from the activity acquired by the previously inactive water. The ratio of these two gives the condensation coefficient, $\alpha$.

A difficulty which arises is that a tritiated steam mole. cule which has condensed on the liquid may re-evaporate before it is permanently trapped in the receiver. The measured value of $\alpha$ is, therefore, likely to be too low. One way of overcoming this problem is to carry out experiments at various velocities of the water jet and to plot the apparent value of $\alpha$ against the residence time, $\tau$. which is the time the water jet is exposed to the steam. A point should be reached at which the residence time is so short that the possibility of re-evaporation can be ignored. The results obtained so far are shown in Fig. 1. The apparent value of $\alpha$ is still increasing and so smaller

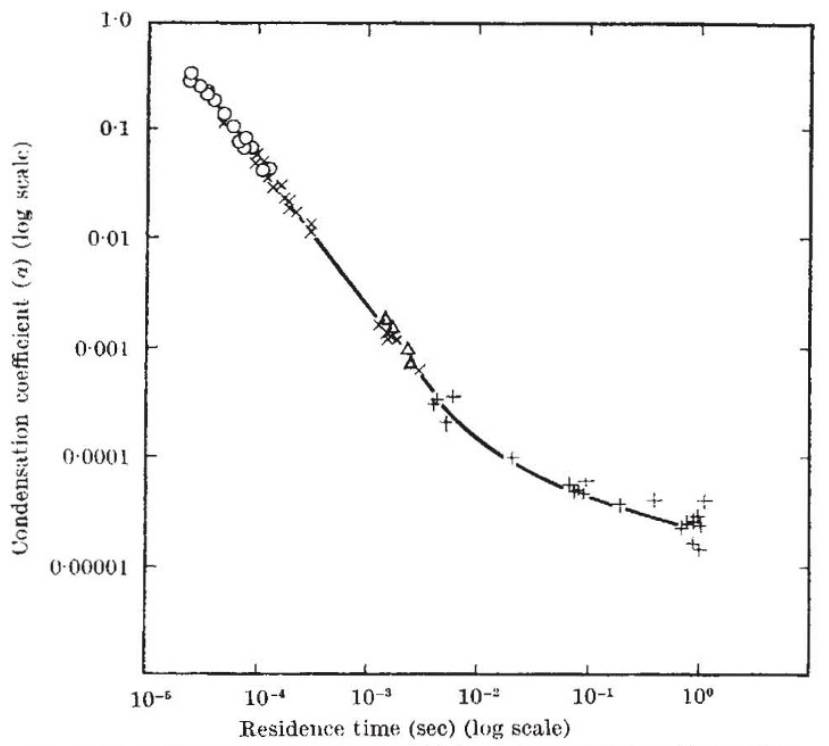

Fig.1. Variation of condensation coefficient of steam with residence time values of $\tau$ are required. It is clear that, under the conditions of this experiment, $\alpha$ exceeds $0 \cdot 305$.

This investigation is still proceeding in an attempt to obtain the true value of the condensation coefficient of water and to explain the discrepancy between it and values obtained by other workers.

\section{1). T. JAMIESON}

Fluids Group,

National Engineering Laboratory, East Kilbride, Glasgow.

${ }^{2}$ Knudsen, M., Ann. Phys. (Leipzig), 47, 697 (1915).

2 Alty, T., and Mackay, C. A., Proc. Roy. Soc., A, 149, 104 (1935).

3 Hickman, K. C. D., Indust. and Eng. Chem., 46, 1442 (1954).

- Silver, R. S., and Simpson, H. C., The Condensation of Superheated Steam 39 (H.M. Stationery Office, 1962).

${ }^{6}$ Silver, R. S., Paper P14/64, presented to the Inst. Mech. Eng., London December 4, 1963.

\section{GEOPHYSICS}

\section{Convection in the Earth's Mantle and the Mechanism of Continental Drift}

Ir has become clear in recent years that there is a formidable case for continental drift. The most convincing single piece of evidence comes from palæo. magnetism ${ }^{1}$, but this is amply supported by a wealth of geological evidence. The only adequate mechanisms for continental drift which have yet been suggested are based on the activity of convection currents in the Earth's mantle.

Runcorn ${ }^{1,2}$ has suggested a mechanism whereby mantle convection currents could cause break-up and separation of continental masses. He supposes that the Earth's core has gradually grown to its present size throughout geological time and, following Chandrasekhar ${ }^{3}$, he postu. lates that the degree of the convection pattern (as represented by spherical harmonics) has progressively changed from an $n=1$ pattern to an $n=5$ pattern as the thickness of the mantle has been progressively reduced. The continents should normally settle over the position of downcurrents and thus each time the convection pattern changes to a higher harmonic the continents are moved to new positions, possibly involving their break-up.

I suggest an alternative mechanism for continental drift, which is also based on the assumptions that convection can occur in the mantle when the adiabatic gradient is exceeded by a sufficient margin to overcome the mechanical resistance to flow and that radiative heat transfer is subordinate to convection. The hypothesis (Fig. 1) has two facets as follows. First, it is argued that the continental regions provide a less-efficient sink for heat rising by convection in the mantle owing to their excess radioactive? heat production; thus convection can take place more readily beneath oceans if other factors are equal. Secondly, it is considered that the normal absence of convection beneath the continents allows a steady increase in the temperature of the mantle beneath the continents owing to radioactive heat sources, which eventually forces convection to take place; the convection may then cause a splitting of the continental region with the formation of new oceanic crust between the blocks which are forced apart, since this is the most efficient way of removing excess heat. These arguments are developed here.

It is assumed that in normal circumstances the upper surface of a convection cell probably lies at a depth of about $50-100 \mathrm{~km}$ beneath the Farth's surface. This assumption is supported by the relative uniformity of oceanic heat flow away from the oceanic ridges and the necessity of the steep temperature gradient due to conduction of heat to extend to depths of the order of $60 \mathrm{~km}$ to enable the local production of basalt magma.

The heat discharged by a rising convection current is conveyed to the Earth's surface partly by thermal con- 